\title{
Assessment of Coping Strategies Among Family Caregivers of Psychotic Patients
}

\author{
Amal Abd Elaal Mohmed ${ }^{1}$, Alaa El Din M. Darweesh², Ikram Ibraheem Mohamed ${ }^{3}$, Zamzam Ahmed \\ Ahmed ${ }^{4}$. \\ 1. Assistant lecturer of Psychiatric \& Mental Health Nursing, Faculty of Nursing, South Valley University, Egypt. \\ 2. Professor of Psychiatry, Faculty of Medicine, Assiut University, Egypt. \\ 3. Professor of Psychiatric and Mental Health Nursing Nursing, Faculty of Nursing, Assiut University, Egypt. \\ 4. Professor of Psychiatric and Mental Health Nursing Nursing, Faculty of Nursing, Assiut University, Egypt.
}

\begin{abstract}
Background: Coping is understood as the process of managing external or internal demands that are considered as taxing or exceeding the resources of the person. There is no formal classification of coping strategies, and these are understood as adaptive versus maladaptive. Aim: To assess coping strategies of family caregivers of psychotic patients. Subjects and Method: A descriptive correlation design using a convenience sample of family caregivers of 100 of psychotic patients recruited from the Psychiatry and Neurology Hospital at Assiut University. Tools: Socio- demographic characteristics of family caregivers and Coping Strategies Inventory Short - Form (CSI-SF) were used. Findings: Caregivers use emotion focused engagement strategies more than other subscales with a mean

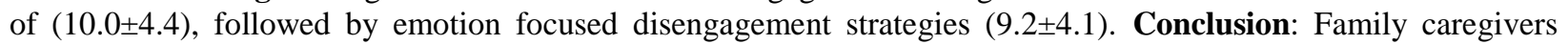
greatly used emotion focused engagement and emotion focused disengagement to cope with their psychotic patients. Recommendation: Further studies is needed to explore the relation between socio-demographic characteristics and coping strategies of family caregivers of psychotic patients
\end{abstract}

\section{Keywords: Coping, Family Caregivers \& Psychotic Patients.}

\section{Introduction}

Generally, when people are stressed by something, their aim is to alter either the circumstances or their interpretation in order to feel more comfortable (Jung Bauer et al., 2003). Coping with a mentally ill patient can be difficult, and many families believe that they do not have the necessary coping strategies to deal with their psychotic patients (Saunders, 2003).

A person can cope on different levels, including physical, social, cognitive, and emotional levels. Using coping mechanisms refers to overcoming or managing stress by mobilizing internal and external resources. Internal resources include one's repertoire of mechanisms such as ego function and neurobiological factors, whereas external resources include social support and cultural factors. (Cotton et al., 2013) .

Coping is defined as the person's constantly changing cognitive and behavioral efforts to manage specific external and/or internal demands that are appraised as taxing or exceeding the person's resources (Strongman, 2006) Also, coping is the things people do (acting or thinking) to increase a sense of wellbeing in their lives and to avoid being harmed by stressful demands (Parasar et al., 2015).

Understanding ways in which carers cope with this burden is not only important for providing them with support, but may improve patient outcomes. Caregivers use a range of strategies to deal with behavioral change associated with mental illness
(O'Brien et al., 2009) Coping strategies are an immense repertoire of defenses to maintain control and balance in the face of stress. It has been also conceptualized as changing one's cognitions and behavior in order to address stressful situations. Two major categories of coping strategies are widely recognized: Problem-focused strategies and emotionfocused strategies (Marimbe et al., 2016). Each problem and emotion focused coping divided in to two categories engagement and disengagement. Engagement category of coping reflects coping strategies in which a person faces the stressor and/or its related emotions, while the disengagement category of coping involves strategies that are aimed at diverting from the stressor and/or its related emotions (Dijkstra \& Homan, 2016).

Problem-focused coping is aimed at changing or eliminating the source of the stress (e.g, taking control, information seeking, and evaluating the pros and cons). On the other hand, emotion-focused coping is oriented toward managing the emotions that accompany the perception of stress (e.g, seeking social support , using avoidance, distancing, releasing emotions out, distracting oneself, managing hostile feelings, using systematic relaxation procedures) (Carver, 2011).

Typically, caregivers use a mixture of several types of coping methods, which may change over time. All these methods can prove useful, but some claim that those using problem-focused coping methods will adjust better to life. Problem-focused coping 
mechanisms may allow an individual greater perceived control over their problem, whereas emotion-focused coping may sometimes lead to a reduction in perceived control (maladaptive coping) (Taylor, 2006). Also, it can be reported reduction in family burden over time among relatives who adopted less emotion-focused coping strategies. Khajavi et al., (2011) found a positive relationship between the extent of burden and use of emotionalcentered, low effective and ineffective coping approaches.

Concerning relation between socio-demographic characteristics and coping strategies, studies suggest that problem-focused coping strategies were more frequently used by young relatives of psychotic patients. Also, caregiver's gender has a significant influence on coping patterns. Female caregivers were found to be using problem-focused and seekingsupport strategies more often, and avoidance less often. Married caregivers more often seek spiritual help (Grover et al, 2015).

\section{Significance of the study}

Family caregiver of psychotic patients experiences considerable stress when dealing with psychotic patients and needs help in coping with it. The caregivers develop different kinds of coping strategies to deal with their patients. An unhealthy coping style is likely to adversely affect the caregiving function. The caregivers develop different kinds of coping strategies to deal with the burden which include finding a reasonable solution, looking for support from friends or other near ones, or trying to avoid the situation by indulging in activities like smoking or substance abuse (Ohaeri \& Fido 2001). Caregivers experience higher levels of burden when they have limited coping resources (Jungbauer et al., 2003). Hence, it is important for psychiatric mental health nurse to take care of the needs of the family caregivers and teach them adaptive coping strategies.

\section{Aim of study}

To assess coping strategies of family caregivers of psychotic patients.

\section{Research question}

What are the most frequent types of coping strategies used by family caregivers of psychotic patients?

\section{Material \& Method}

Study design

A descriptive correlational design was followed in this study.

\section{Setting}

The study was conducted at the outpatient clinic and inpatient department in the Psychiatry and
Neurology Hospital at Assiut University which services all governorates of Upper Egypt being the only currently specialized in psychiatric medicine.

\section{Subjects}

A convenient sample of family caregivers of one hundred (100) psychotic patients were recruited with a total number of 141 caregivers.

\section{Inclusion criteria}

- A family caregiver who provides any type of physical, economic and/or emotional care for his psychotic patient and is living permanently with the patient at home.

- A caregiver who care for a patient with psychotic disorder as schizophrenia, mood disorder with psychotic features, schizoaffective disorder, delusional disorder, or brief psychotic disorder.

\section{Exclusion criteria}

- Caregivers of patients with dual diagnosis as (substance/medication-induced psychotic disorder).

- Caregivers with chronic medical illness themselves.

\section{Tools}

a) Socio- demographic and Clinical data sheet

This tool was developed by the researcher. It elicits personal data of family caregivers as age, sex, occupation, marital status, residence, income, level of education, and kinship.

b) Coping Strategies Inventory Short - Form (CSI-SF)

It was developed by Addison et al, (2007) to assess coping thoughts and behaviors in response to stressful situations. It consists of 16 items, fed on a five point Likert scale ranging from $\mathbf{1}=$ "Never", 2 = "Seldom", 3= Sometimes", $4=$ "Often" and 5 = "Almost Always ." Each items distributed on 4 subscales; problem focused engagement, problem focused disengagement, emotion focused engagement, and emotion focused disengagement and each contained four items. Caregivers receive a score for each subscale that ranges from $4-20$. This tool was tested for translation and content validity by a jury of five experts in the field of Psychiatric Medicine and Psychiatric Mental Health Nursing, and necessary corrections were done accordingly.

Procedure

An official permission to carry out the study was obtained from the director of Psychiatry and Neurology Hospital.

Pilot study

A pilot study was carried out on a group of ten family caregivers of psychotic patients. Family caregivers were interviewed individually by using sociodemographic and clinical data sheet, and Coping Strategies Inventory Short - Form (CSI-SF). Also, 
reliability test was done for this tool by using chronbach's alpha test ant it was 0.71 to 0.82

\section{Ethical considerations}

- Research proposal was approved by the ethical committee of Assiut faculty of nursing.

- There is no risk for the study subjects during application of the research.

- The study followed common ethical principles in clinical research.

- Informed oral consent was obtained from each caregiver who agreed to participate in the study after explaining the purpose of the study.

- Subjects were told that they have the right to withdraw from the study without any rationale at any time.
- Privacy and confidentiality were assured during the whole study steps.

Statistical analysis

- The raw data were assorted, coded and transferred into special format for computer feeding.

- The data were fed into the computer using the Statistical Package of Social Sciences (SPSS version 20).

- Statistical analysis tests included mean, standard deviation, Anova, and T-test.

- The level of significance used for the study was P value less than 0.05 .

\section{Results}

Table (1): Socio-demographic characteristics of family caregivers of patients with psychosis $(\mathrm{n}=141)$.

\begin{tabular}{|c|c|c|}
\hline Socio-demographic characteristics of family caregivers & $\mathrm{N}=\mathbf{1 4 1}$ & $\%$ \\
\hline $\begin{array}{l}\text { Age groups } \\
15-<30 \\
30-<45 \\
45-<60 \\
60-<75\end{array}$ & $\begin{array}{l}25 \\
22 \\
59 \\
35\end{array}$ & $\begin{array}{r}17.7 \\
15.6 \\
\mathbf{4 1 . 9} \\
24.8\end{array}$ \\
\hline $\begin{array}{l}\text { Range } \\
\text { Mean } \pm \text { SD }\end{array}$ & $\begin{array}{c}15-70 \\
46.9 \pm 14.7\end{array}$ & \\
\hline $\begin{array}{l}\text { Sex } \\
\text { Male } \\
\text { Female }\end{array}$ & $\begin{array}{l}47 \\
94\end{array}$ & $\begin{array}{l}33.3 \\
66.7\end{array}$ \\
\hline $\begin{array}{l}\text { Education } \\
\text { Illiterate } \\
\text { read and write } \\
\text { Secondary } \\
\text { University }\end{array}$ & $\begin{array}{c}92 \\
18 \\
23 \\
8\end{array}$ & $\begin{array}{c}\mathbf{6 5 . 2} \\
12.8 \\
16.3 \\
5.7\end{array}$ \\
\hline $\begin{array}{l}\text { Occupation } \\
\text { Employee } \\
\text { Skilled workers } \\
\text { Non skilled workers } \\
\text { No work } \\
\end{array}$ & $\begin{array}{c}12 \\
13 \\
12 \\
104\end{array}$ & $\begin{array}{c}8.5 \\
9.2 \\
8.5 \\
\mathbf{7 3 . 8}\end{array}$ \\
\hline $\begin{array}{l}\text { Marital status } \\
\text { Single } \\
\text { Married } \\
\text { Widow } \\
\text { Divorce }\end{array}$ & $\begin{array}{c}17 \\
93 \\
28 \\
3\end{array}$ & $\begin{array}{c}12 \\
\mathbf{6 6} \\
19.9 \\
2.1\end{array}$ \\
\hline $\begin{array}{l}\text { Kinship } \\
\text { Mother } \\
\text { Father } \\
\text { Brother/Sister } \\
\text { Husband/Wife } \\
\text { Uncle/Aunt } \\
\text { Daughter/Son }\end{array}$ & $\begin{array}{c}56 \\
24 \\
26 \\
21 \\
3 \\
11\end{array}$ & $\begin{array}{c}39.7 \\
17.1 \\
18.4 \\
14.9 \\
2.1 \\
7.8\end{array}$ \\
\hline $\begin{array}{l}\text { Residence } \\
\text { Rural } \\
\text { Urban }\end{array}$ & $\begin{array}{c}121 \\
20\end{array}$ & $\begin{array}{l}\mathbf{8 5 . 9} \\
14.2\end{array}$ \\
\hline $\begin{array}{l}\text { Income } \\
\text { No fixed income } \\
\text { Insufficient } \\
\text { Sufficient }\end{array}$ & $\begin{array}{l}61 \\
59 \\
21\end{array}$ & $\begin{array}{l}\mathbf{4 3 . 3} \\
41.8 \\
14.9\end{array}$ \\
\hline
\end{tabular}


Table (2): Family caregivers 'scores on coping strategies inventory $(n=141)$.

\begin{tabular}{|l|c|c|c|}
\hline \multicolumn{1}{|c|}{ Coping strategies subscales } & $\begin{array}{c}\text { Range of original } \\
\text { scoring of coping } \\
\text { strategies subscales }\end{array}$ & $\begin{array}{c}\text { Range of } \\
\text { coping score of } \\
\text { caregivers }\end{array}$ & Mean \pm SD \\
\hline Problem focused engagement & $4-20$ & $4-19$ & $7.2 \pm 3.4$ \\
\hline Problem focused disengagement & $4-20$ & $4-20$ & $8.7 \pm 4.5$ \\
\hline Emotion focused engagement & $4-20$ & $4-19$ & $\mathbf{1 0 . 0 \pm 4 . 4}$ \\
\hline Emotion focused disengagement & $4-20$ & $4-20$ & $9.2 \pm 4.1$ \\
\hline
\end{tabular}

Table (3): Correlation between caregivers coping strategies mean scores and their socio-demographic characteristics $(\mathrm{N}=141)$.

\begin{tabular}{|c|c|c|c|c|}
\hline \multirow[b]{2}{*}{$\begin{array}{r}\text { Socio-demographic } \\
\text { Characteristics of } \\
\text { caregivers }\end{array}$} & \multicolumn{4}{|c|}{ Caregivers coping strategies } \\
\hline & $\begin{array}{c}\text { Problem } \\
\text { focused } \\
\text { engagement }\end{array}$ & $\begin{array}{l}\text { Problem focused } \\
\text { disengagement }\end{array}$ & $\begin{array}{c}\text { Emotion } \\
\text { focused } \\
\text { engagement }\end{array}$ & $\begin{array}{l}\text { Emotion focused } \\
\text { disengagement }\end{array}$ \\
\hline *Range of scoring & $(4-20)$ & $(4-20)$ & $(4-20)$ & $(4-20)$ \\
\hline Age groups & & Mean \pm SD & & \\
\hline $15-<30$ & $6.8 \pm 3.0$ & $8.2 \pm 4.56$ & $11.4 \pm 3.4$ & $8.6 \pm 4.3$ \\
\hline $30-<45$ & $7.6 \pm 3.7$ & $9.4 \pm 4.8$ & $10.9 \pm 4.4$ & $9.4 \pm 3.8$ \\
\hline $45-<60$ & $6.6 \pm 2.5$ & $9.1 \pm 4.7$ & $10.1 \pm 4.7$ & $9.2 \pm 4.3$ \\
\hline $60-<75$ & $8.1 \pm 4.3$ & $8.0 \pm 4.0$ & $8.3 \pm 4.2$ & $9.4 \pm 3.9$ \\
\hline $\mathbf{F}$ & 1.63 & 0.63 & 2.8 & 0.26 \\
\hline p-value & 0.1 & 0.5 & 0.04 & 0.8 \\
\hline $\begin{array}{r}\text { Sex } \\
\text { Male } \\
\text { Female } \\
\mathbf{T} \\
\end{array}$ & $\begin{array}{c}\mathbf{8 . 1} \mathbf{4} \mathbf{4 . 1} \\
6.7 \pm 2.8 \\
2.39 \\
\end{array}$ & $\begin{array}{l}7.6 \pm 4.1 \\
9.2 \pm 4.7 \\
-1.98- \\
\end{array}$ & $\begin{array}{c}9.9 \pm 4.2 \\
10.1 \pm 4.6 \\
-0.33- \\
\end{array}$ & $\begin{array}{c}\mathbf{9 . 4} \pm \mathbf{3 . 5} \\
9.2 \pm 4.4 \\
0.29 \\
\end{array}$ \\
\hline P-value & 0.000 & 0.07 & 0.5 & 0.03 \\
\hline $\begin{array}{r}\text { Occupation } \\
\text { Employee } \\
\text { Skilled workers } \\
\text { Non skilled workers } \\
\text { No work } \\
\mathbf{F} \\
\end{array}$ & $\begin{array}{c}8.2 \pm 4.2 \\
7.1 \pm 3.1 \\
6.6 \pm 2.5 \\
7.1 \pm 3.4 \\
0.48 \\
\end{array}$ & $\begin{array}{c}9.1 \pm 5.0 \\
6.2 \pm 3.1 \\
7.1 \pm 2.8 \\
9.1 \pm 4.7 \\
2.2 \\
\end{array}$ & $\begin{array}{c}11.3 \pm 4.6 \\
9.8 \pm 4.6 \\
10.0 \pm 3.9 \\
9.9 \pm 4.5 \\
0.38\end{array}$ & $\begin{array}{c}9.2 \pm 4.5 \\
9.7 \pm 3.8 \\
9.3 \pm 3.6 \\
9.2 \pm 4.2 \\
0.06 \\
\end{array}$ \\
\hline P-value & 0.7 & 0.09 & 0.8 & 1.0 \\
\hline $\begin{array}{r}\text { Education } \\
\text { Illiterate } \\
\text { Read and write } \\
\text { Secondary } \\
\text { University } \\
\text { p-value }\end{array}$ & $\begin{array}{c}6.6 \pm 2.5 \\
9.1 \pm 4.2 \\
6.6 \pm 3.5 \\
\mathbf{1 1 . 4 \pm 4 . 8} \\
\mathbf{0 . 0 0 0}\end{array}$ & $\begin{array}{c}8.7 \pm 4.4 \\
\mathbf{1 1 . 2} \pm 4.9 \\
6.7 \pm 3.8 \\
8.9 \pm 4.9 \\
\mathbf{0 . 0 1}\end{array}$ & $\begin{array}{c}9.8 \pm 4.3 \\
10.4 \pm 4.6 \\
10.0 \pm 4.7 \\
11.5 \pm 4.8 \\
0.7\end{array}$ & $\begin{array}{c}9.5 \pm 4.2 \\
7.2 \pm 2.6 \\
\mathbf{1 0 . 9} \pm \mathbf{4 . 5} \\
6.4 \pm 2.2 \\
\mathbf{0 . 0 0 5}\end{array}$ \\
\hline
\end{tabular}

$N: B$ high mean score means high using of coping strategies

*Range of scoring = minimum and maximum score of each subscale of coping strategies 
Table (3): Correlation between caregivers coping strategies mean scores and their socio-demographic characteristics of family caregivers $(\mathrm{N}=141)$ cont.

\begin{tabular}{|l|c|c|c|c|}
\hline $\begin{array}{c}\text { Socio-demographic } \\
\text { characteristics of family } \\
\text { caregivers }\end{array}$ & $\begin{array}{c}\text { Croblem focused } \\
\text { engagement }\end{array}$ & $\begin{array}{c}\text { Problem focused } \\
\text { disengagement }\end{array}$ & $\begin{array}{c}\text { Emotion focused } \\
\text { engagement }\end{array}$ & $\begin{array}{c}\text { Emotion focused } \\
\text { disengagement }\end{array}$ \\
\hline *Range of scoring & $(4-20)$ & $(4-20)$ & $(4-20)$ & $(4-20)$ \\
\hline Marital status & & Mean \pm SD & & \\
\hline Single & $7.1 \pm 3.1$ & $9.5 \pm 4.8$ & $10.7 \pm 3.3$ & $8.0 \pm 3.7$ \\
\hline Married & $7.6 \pm 3.7$ & $8.8 \pm 4.7$ & $10.1 \pm 4.5$ & $9.2 \pm 4.0$ \\
\hline Widow & $6.1 \pm 1.9$ & $7.9 \pm 4.1$ & $9.3 \pm 4.9$ & $10.3 \pm 4.6$ \\
\hline Divorced & $5.00 \pm 0.0$ & $8.3 \pm 3.2$ & $9.7 \pm 5.0$ & $9.00 \pm 5.6$ \\
\hline F & 1.86 & 0.42 & 0.39 & 1.2 \\
\hline P-value & 0.1 & 0.5 & 0.7 & 0.2 \\
\hline kinship & & & & \\
Mother & $6.4 \pm 2.2$ & $9.2 \pm 4.8$ & $9.8 \pm 4.9$ & $9.8 \pm 4.5$ \\
Father & $\mathbf{9 . 2 \pm 4 . 8}$ & $7.8 \pm 4.5$ & $9.4 \pm 4.2$ & $8.7 \pm 2.9$ \\
Brother/sister & $7.2 \pm 3.1$ & $9.5 \pm 4.9$ & $11.5 \pm 3.6$ & $7.9 \pm 3.7$ \\
husband/wife & $6.2 \pm 2.9$ & $7.6 \pm 4.0$ & $8.9 \pm 4.6$ & $10.5 \pm 4.5$ \\
Uncle/aunt & $8.3 \pm 2.5$ & $9.0 \pm 7.0$ & $14.3 \pm 0.5$ & $7.0 \pm 0.0$ \\
Daughter/son & $8.1 \pm 4.5$ & $8.2 \pm 2.7$ & $10.2 \pm 3.9$ & $8.8 \pm 4.3$ \\
F & 3.1 & 0.8 & 1.6 & 1.5 \\
\hline P-value & $\mathbf{0 . 0 1}$ & 0.6 & 0.2 & 0.2 \\
\hline Residence & & & & \\
\hline Rural & $7.1 \pm 3.2$ & $8.7 \pm 4.5$ & $9.9 \pm 4.3$ & $9.1 \pm 4.1$ \\
\hline Urban & $7.8 \pm 3.9$ & $8.9 \pm 4.7$ & $10.5 \pm 5.1$ & $10.1 \pm 4.4$ \\
\hline T & -0.9 & -0.2 & -0.5 & -1.0 \\
\hline P-value & 0.4 & 0.9 & 0.6 & 0.3 \\
\hline Income & & & & \\
\hline No fixed income & $6.8 \pm 2.7$ & $9.6 \pm 4.9$ & $10.7 \pm 4.2$ & $8.9 \pm 4.3$ \\
\hline In sufficient & $7.5 \pm 3.8$ & $8.1 \pm 4.2$ & $9.1 \pm 4.8$ & $9.5 \pm 3.9$ \\
\hline Sufficient & $7.3 \pm 3.6$ & $7.9 \pm 4.2$ & $10.6 \pm 3.9$ & $9.6 \pm 4.3$ \\
\hline F & 0.7 & 2.0 & 2.2 & 0.4 \\
\hline P-value & 0.5 & 0.1 & 0.1 & 0.7 \\
\hline N:Bhigh & & & \\
\hline
\end{tabular}

$N: B$ high mean score means high using of coping strategies

*Range of scoring= minimum and maximum score of each subscale of coping strategies.

Table (1): Shows that, the age of caregivers ranged between 15 to $<75$ years. More than forty percent of caregivers $(41.9 \%)$ were in the age group 45 to less than 60 years and $66.7 \%$ of caregivers were females. It also shows that, the majority of the caregivers were not working and $65.2 \%$ of them were illiterate. As regards marital status, $66 \%$ of caregivers were married mothers constituted the highest percentage (39.7\%) of caregivers. Most of caregivers (85.9\%) were living in rural areas, $43.3 \%$ had no fixed income, while another $41.8 \%$ had insufficient income.

Table (2): Shows that, the most frequently used strategy by caregivers was emotion focused engagement (10.0 \pm 4.4 ), followed by emotion focused disengagement $(9.2 \pm 4.1)$.

Table (3): Showed that caregivers aged $15-<30 \mathrm{yrs}$ were the highest to significantly use emotional focused engagement coping strategies more than other age group $(\mathrm{p}=0.04)$. However, male caregivers were the highest to significantly use problem focused engagement $(p=0.000)$ followed by emotional focused disengagement coping strategies $(\mathrm{p}=0.03)$ more than female.

Regarding education, it can be noted that, caregivers with university education significantly use more problem focused engagement strategy $(\mathrm{p}=0.000)$ than other less educated caregivers. Those who can only read and write were significantly the highest among those used problem focused disengagement strategy $(\mathrm{p}=0.01)$. Those with secondary school education were significantly using emotion focused disengagement strategy $(\mathrm{p}=0.005)$, and illiterate caregivers use emotion focused coping more than problem focused coping. 
Table (3): Also, shows that, fathers as caregivers had significantly more tendency to use problem focused engagement coping strategies $(p=0.01)$. On the other hand, occupation, marital status, residence, and income of the caregivers were not significantly affecting their coping strategies. However those who live in urban areas, have no fixed income, and those with sufficient income had higher mean scores on emotion focused engagement $(10.5 \pm 5.1,10.7 \pm 4.2, \& \quad 10.6 \pm 3.9)$ respectively, though insignificant.

\section{Discussion}

The current result revealed that family caregivers significantly used emotion focused coping strategy. Emotion-focused coping is a mechanism to alleviate distress by minimizing, reducing, or preventing, the emotional components of a stressor. This might be related to that the majority of caregivers were females. They are closed physically and emotionally to their patients and had more burden than male. This finding is supported by the finding of the study conducted by Papastavrou et al., (2007) who reported that highly burdened caregivers tended to resort to emotion-focused coping strategies. Also, Etters et al. (2008) reported that female caregivers tended to report more emotion-focused coping, while males reported problem-focused coping strategies. A study of family members of patients with psychotic disorders found that escape; distancing and rumination were main strategies of coping as emotion focused coping (Cotton et al., 2013). In contrast, Nehra et al., (2005) reported that the most commonly coping strategies used by caregivers of psychotic disorders were consulting doctors, and seeking practical help as problem focused coping.

The present study showed that, younger age caregivers significant used emotion - focused engagement coping rather than other ways of coping. This could be interpreted by that younger age caregivers had a few skills in dealing with stressors and had no experiences in problem solving so, they use emotion coping. On the other hand, Bauer et al, (2013) reported that younger age caregivers use religiousness and searching for meaning as a problem focused disengagement coping. One possible explanation of this finding is that younger caregivers may be confronted directly for the first time in their lives with suffering and powerlessness and may thus gain more inner strength and experience more character development than older caregivers, who often have already learned to cope by dealing with personal crises . Moreover, Aggarwal et al., (2009) reported that greater use of problem focused and seeking support coping strategies were associated with higher positive personal caregiving experience. Regarding level of education, it was found that caregivers with university education use problem focused engagement. This may be related to that highly educated caregivers had problem solving techniques, learned adaptive coping skills, relaxation techniques, seeking social and psychological support to tackle burden. Higher levels of education empower better coping mechanisms. This finding is consistent with Ghane et al., (2016) who reported that highly educated caregivers learn coping strategies that help them to gain more control, not only over stressful situations, but also over their own behaviors and time management, and allowing them to feel less burdened in all aspects of their lives. In this regard, Magana et al., (2007) reported that caregivers who have more education would broaden their knowledge and they have ability to adapt to a stressful situation.

Concerning kinship, this result revealed that father as a caregiver use problem focused engagement more than other relatives. It might be related to males more often engage in direct action and confrontation as a means of coping. In the same line, Marceau et al., (2015) reported that fathers used more problem focused coping than mothers.

The present study revealed that, there is no significant association between occupation, marital status, residence, and income of caregivers and their coping strategies .This study is consistent with, Hassan et al., (2011), who reported that there was no significant relation between coping strategies and socio-demographic data.

\section{Conclusion \& Recommendations}

Based on the results of the present study it can be concluded that, family caregivers of psychotic patients greatly used emotion focused engagement strategies followed by emotion focused disengagement strategies to cope with their psychotic patients.

Based on the results of the current study, the following recommendation are suggested: Further studies is needed to explore the relation between socio-demographic characteristics and coping strategies of family caregivers of psychotic patients.

\section{References}

1. Addison, C., Campbell-Jenkins, B., Sarpong, D., Kibler, J., Singh, M., Dubbert, P., Taylor, H., (2007): Correction: Addison, C.C., et al. Psychometric Evaluation of a Coping Strategies Inventory Short-Form (CSI-SF) in the Jackson Heart Study Cohort. Int. J. Environ. Res. Public Health , 4, 243-249. International Journal of Environmental Research and Public Health, 
Vol. (6), No. (3), Pp.941-942. doi:10.3390/ijerph6030941.

2. Aggarwal, M., Avasthi, A., Kumar, S., \& Grover, S., (2009): Experience of Caregiving in Schizophrenia: a Study from India. International Journal of Social Psychiatry, Vol. (57), No.(3), Pp.224-236. doi:10.1177/0020764009352822.

3. Bauer, R., Sterzinger, L., Koepke, F., \& Spiessl, H. (2013): Rewards of Caregiving and Coping Strategies of Caregivers of Patients with Mental Illness. Psychiatric Services, Vol. (64), No. (2), Pp. 185-188. doi:10.1176/appi.ps.001212012.

4. Carver, C., (2011): Coping. In R. J. Contrada \& A. Baum (Eds.), The Handbook of Stress Science: Biology, Psychology, and Health. (220-229). New York: Springer Publishing Company.)

5. Cotton, S., McCann, T., Gleeson, J., Crisp, K., Murphy, B., \& Lubman, D., (2013): Coping strategies in carers of young people with a first episode of psychosis. Schizophrenia Research, Vol. (146), No. (1-3), Pp.118-124. doi:10.1016/j.schres.2013.02.008.

6. Dijkstra, M., \& Homan, A., (2016): Engaging in Rather than Disengaging from Stress: Effective Coping and Perceived Control. Frontiers in Psychology, 7. doi:10.3389/fpsyg.2016.01415

7. Etters, L., Goodall, D., \& Harrison, B., (2008): Caregiver burden among dementia patient caregivers: A review of the literature. Journal of the American Academy of Nurse Practitioners, Vol. (20), No (8), Pp.423-428. doi:10.1111/j.1745-7599.2008.00342.x.

8. Ghane, G., Ashghali Farahani, M., Seyedfatemi, N., \& Haghani, H., (2016): Effectiveness of Problem-Focused Coping Strategies on the Burden on Caregivers of Hemodialysis Patients. Nursing and midwifery studies, Vol. (5), No. (2), e35594. doi:10.17795/nmsjournal35594.

9. Grover, S., Pradyumna, \& Chakrabarti, S. (2015). Coping among the caregivers of patients with schizophrenia. Industrial Psychiatry Journal, 24(1), 5-11. doi:10.4103/0972-6748.160907.

10. Hassan, W., Mohamed, I., AbdElnaser, A., \& Sayed, N., (2011): Burden and coping strategies in caregivers of schizophrenic patients. Journal of American Science, Vol. (7), No. (5), Pp. 802-811.

11. Jungbauer, J., Wittmund, B., Dietrich, S., \& Angermeyer, M., (2003): Subjective burden over 12 months in parents of patients with schizophrenia. Archives of Psychiatric Nursing, 17(3), 126-134. doi:10.1016/s08839417(03)00056-6.
12. Magana, $\mathbf{S}$. Ramirez Garcia, J., Hernandez, M., \& Cortez, R., (2007): Psychological Distress among Latino Family Caregivers of Adults with Schizophrenia: The Roles of Burden and Stigma. Psychiatric Services, Vol. (58), No. (3), Pp.378-384. doi:10.1176/appi.ps.58.3.378.

13. Marceau, K., Zahn-Waxler, C., Shirtcliff, E., Schreiber, J., Hastings, P., \& KlimesDougan, B., (2015): Adolescents', mothers', and fathers' gendered coping strategies during conflict: Youth and parent influences on conflict resolution and psychopathology. Development and Psychopathology, 27(4pt1), 1025-1044. doi:10.1017/s0954579415000668

14. Marimbe, B., $\quad$ Cowan, F., $\quad$ Kajawu, L., Muchirahondo, F., \& Lund, C. (2016): Perceived burden of care and reported coping strategies and needs for family caregivers of people with mental disorders in Zimbabwe. African Journal of Disability, Vol. (5), No. (1). doi:10.4102/ajod.v5i1.209

15. Nehra, R., Chakrabarti, S., Kulhara, P., \& Sharma, R. (2005): Caregiver-coping in bipolar disorder and schizophrenia. Social Psychiatry and Psychiatric Epidemiology, Vol. (40), No. (4), 329-336. doi:10.1007/s00127-005-0884-3.

16. O'Brien, M., Zinberg, J., Ho, L., Rudd, A., Kopelowicz, A., Daley, M., Cannon, T., (2009): Family problem solving interactions and 6-month symptomatic and functional outcomes in youth at ultra-high risk for psychosis and with recent onset psychotic symptoms: A longitudinal study. Schizophrenia Research, Vol. (107), No. (2-3), Pp.198-205. doi:10.1016/j.schres.2008.10.008.

17. Ohaeri, J., \& Fido, A., (2001): The opinion of caregivers on aspects of schizophrenia and major affective disorders in a Nigerian setting. Social Psychiatry and Psychiatric Epidemiology, 36(10), 493-499. doi:10.1007/s001270170014.

18. Papastavrou, E., Kalokerinou, A., Papacostas, S., Tsangari, H., \& Sourtzi, P. (2007): Caring for a relative with dementia: family caregiver burden. Journal of Advanced Nursing, Vol. (58), No.(5), Pp.446-457.

19. Parasar, A., Naik, D., Gupta, P., Patel, A., Maurya, A., \& Srivatav, V., (2015): A study of coping strategies caregivers of schizophrenia patients. IAHRW International Journal of Social Sciences Review, 2015, Vol.(3),No.(3), Pp.354359.

20.Saunders, J., (2003): Families Living with Severe Mental Illness: A Literature Review. Issues in Mental Health Nursing, Vol. (24), No (2), Pp. 175-198. doi:10.1080/01612840305301. 
21. Strongman, K., (2006): Applying psychology to everyday life - a beginner's guide, $5^{\text {th }}$ edition, chapter 1, England: John Wiley \&Sons Ltd.

22. Taylor, S., (2006): Health Psychology, international edition. McGraw-Hill Education, pg. 193 